\title{
The Cultivation Path of Craftsman's Spirit in Application-oriented Undergraduate Education
}

\author{
Wenbin Sun \\ Institute of Higher Education \\ Huaiyin Institute of Technology \\ Huai'an, China \\ Email: sunwb1969@hyit.edu.cn
}

\author{
Huasheng Sun \\ Faculty of Architecture and Civil Engineering \\ Huaiyin Institute of Technology \\ Huai'an, China \\ Email: sunhuasheng@hyit.edu.cn
}

\begin{abstract}
In China, higher engineering education is moving into a new stage of connotation development and quality promotion. How to train the craftsman's spirit has become a hot issue recently. The unity of knowledge, value orientation and craftsman's spirit into application-oriented talent cultivation can adapt to the trend of Chinese manufacturing development and China Made 2025, meet the requirements of the schoolrunning orientation, survival and development in the application-oriented universities and colleges, and benefit the improvement of application-oriented undergraduates' comprehensive quality and the development of students' professional careers. Through enhancing curriculum setting and specialty building and boosting the combination of production and teaching together with some other methods, the cultivation of craftsman's spirit is to be integrated into each process. For a long time, there are certain separations between quantity and quality, infrastructural investment and educational soft power, educational process and vocational elements, and educational levels and talent growth rules in the cultivation of application-oriented talents and the education of application-oriented universities.
\end{abstract}

Keywords: craftsman's spirit; application-oriented talents; application-oriented university; cultivation path

\section{INTRODUCTION}

In 2016, the Government Work Report of Chinese Premier Li Keqiang mentioned that enterprises were encouraged to develop personalized customization, flexible production, and cultivate the craftsman' spirit ${ }^{[1]}$. In 2017, the Government Work Report of Premier Li asked again the enterprises should carry forward the craftsman's spirit, strengthen the craftsmen fulfill professional personal integrity, advocate the excelsior spirit, cultivate more Chinese Craftsmen, create more famous China Brand in the world, and promote Chinese economic development into the era of quality ${ }^{[2]}$. With the development of economy and the progress of society, the craftsman's spirit shows the quality of keeping pace with the Times, and has an important value of the Times. However, examining the craftsmen of career preparation phase, or career starting point and education practice, we may find that the current education system has the material conditions of application-oriented talent cultivation, still has a big gap for improvement in the mental condition and on the cultural atmosphere ${ }^{[3]}$. In a certain degree, this mismatch between the materials condition and mental condition may cause the split and gap between craftsmen training and spirit cultivation.

China Made and China Brand are in desperate need of numerous great craftsmen. The supply-side structural reform of talent training needs the higher engineering education with the craftsman's spirit. Therefore, building the modern application-oriented universities and vocational colleges education system actively adapt to the current social and economic development on the demand for high-skill talents, cultivating the craftsman's spirit in application-oriented universities and vocational colleges is the historical mission of higher engineering education in this new era ${ }^{[4]}$. To explore the reasons behind this phenomenon and the education training path of the craftsman's spirit, this paper provide the theoretical support and education practice of the cultivation of the craftsman's spirit in application-oriented undergraduate education.

\section{DISSONANCE AND CAUSES ANALYSIS IN EDUCATION OF CRAFTSMAN'S SPIRIT}

More than 40 years after the resumption of the college entrance examination, Chinese higher education has gradually translated from elite education to popularization education. Chinese higher education developed rapidly, but it also revealed some deficiencies. In the latest two or three decades, many universities and colleges have attached great importance to knowledge training and skills promotion, ignore professional ethics, occupational group, relations of profession and culture. This dissonance between the craftsman training and spirit cultivation is quietly influencing the career education object and its contribution to the society.

\section{A. The Features on the Dissonance in Craftsman-spirit Education}

Education dissonance appeared firstly between quantity and quality. This mismatch mainly showed that the quantity expansion was much faster than the quality improvement. At present, the total amount of Chinese higher education has ranked first in the world, and reached a historical higher point. The country's education institutions have developed the hundreds of millions of industry practitioners, and have the huge human resource and social foundation for the 
growth of high-skill talents, but students who experienced the professional process and career cultivation rarely become the industry authorities and technical masters. After graduation, students who concentrated on a certain industry or field for a long time can rarely realize their career dreams. In Chinese higher engineering education, there is a structural failure that the training of high-skill talents does not meet the needs of social economy at all levels, including macro-level, middle-level and micro-level. Equilibrium problems, in the application-oriented universities and vocational colleges, employment quality, job satisfaction, such as data structure and the turnover rate of employment, is essential a mismatch of the quantity and quality in higher engineering education.

The second dissonance lied in the disequilibrium between educational investment and educational output. This mismatch showed an improper tendency that strengthened the hardware investment and weakened the connotation construction in higher engineering education. In the past period, due to the system, idea, society, history, culture and other factors, some administrative departments, applicationoriented universities and vocational colleges paid more attention to the campus building, equipment investment, this led to a unilateral payment in the school-running practice bases and hardware input, ignored the educational philosophy spirit, campus culture and ethics environment construction, thus raise in the high-skill talents was never the fusion of cultural power. In this educational environment, the talents even grown up with superb skills, they were also difficult to realize the high-skill talents with rightful professionalism in key positions and played leading roles in key areas. Such education environment obviously violated the development law of education and the purpose of talent cultivation.

The most important dissonance was that the education process was out of harmony with the occupational factors. This mismatch presented the emphasizing skill training and neglecting professional attitude cultivation in education process. As the three elements of professional ability, knowledge, skills and attitudes should be harmonious, unified, and internalized into the cultivation of professional talent in application-oriented universities and vocational colleges, cultivation process, career development, students' growth should also be comprehensive to understand and comply with the requirements of vocational ability and law of development to carry out personnel training activities. However, the current practice of education, especially the professional education activity, has given a large proportion to the teaching of knowledge and skills, while it is relatively different in the formation and shaping of professional attitude. This tendency deviated from the path of professional competence and was not conducive to an individual growth of education object and the future career development.

\section{B. The Causes of the Dissonance in Craftsman-spirit Education}

For a long time, because of misunderstanding of the craftsman-spirit education in the whole society, Chinese higher engineering education ignored the attention and study of the craftsman's spirit. This phenomenon and behavior resulted that the craftsman as a social existence was lack of cognition on the training rules. The dissonance of craftsman and spirit in education practice had its deep understanding causes.

The concept of craftsman has been around since ancient times. To the craftsman's spirit, there are no essential definition and precise connotation in academic circles ${ }^{[5]}$. Presently, educational administrative departments and colleges are lacking in the perceptual cognition and rational thinking on the craftsman's spirit from the education dimensions. The understanding and interpretation of craftsman's spirit mainly stays at the stage of perceptual cognition, such as professional ethics, striving perfection, focusing single-mindedness, and offering dedication. Higher education requires a kind of rational regression, which must be upgraded from perceptual knowledge to rational knowledge. Only in this way can we grasp the essential attribute of craftsman's spirit, the regularity of its cultivation, and the education practice of cultivating craftsman-spirit masters be carried out effectively.

Due to the lack of analytical framework and dimensions, academic research and education practice cannot hold the core principles of craftsman and spirit, and get the evolution regularity of craftsman's spirit. Therefore, they then cannot examine craftsman individual skills and spiritual cultivation and development of dynamic, but also the loss of the social community with the inheritance of mentoring relationship craftsmen of item. The lack of analytical dimensions, comprehensiveness, dynamics and connectedness will also result in the lack of foundation and unscientific research on the social contribution of the craftsman, namely the value inspection of the craftsman's spirit. To craftsman spirit, this lack of cognition in education system has a potential impact on the whole process of education's practice of cultivating people, and finally reflects it through the results of cultivating people and their professional ability.

\section{EDUCARION DIMENSIONS OF CRAFTSMAN'S SPIRIT}

Education dimensions of modern craftsman's spirit refer to the necessity and direction of education practice in the process of educating, teaching, and cultivating high-skill talents. This concept firstly emphasizes two aspects, one is the essence and core connotation of craftsman spirit, and the other is the attribute and development direction of craftsman spirit. As a social existence and social dimension, craftsmen through higher engineering education have their special characteristics, attributes, and representation, we can investigate and express from the physical characteristics, quality and spirit, social relations, and social contribution, etc. In the meantime, we should start from the two aspects of 
craftsmen spirit education to degree analysis of craftsmen as each inspection dimension of social existence, to understand the essence of the spirit and dynamically guide practical activity of education.

The craftsman's spirit was historically born in the age of handicraft industry. It is a precious spiritual heritage of manual workers ${ }^{[6]}$. In Chinese culture, it is usually traditionally characterized by artistic spirit of innovation, work attitude of refinement, and the unity of the principle and technique in life-pursuit, in western culture may be embodied in the pursuit of perfect and great faith ${ }^{[7]}$.

To investigate the emergence of craftsman and the formation of craftsman's spirit, we must put it in the history of handmade production and labor development. In fact, the craftsmen are only a group of manual labors. The craftsmen's spirit is only the spiritual cohesion, and the spiritual heritage of manual workers in the development of handicraft industry. When it came to the mechanical or modern industry, it is often dismissed, even disregarded. Newly, we live in the modern industrial and post-industrial eras; almost all of products are made by machines and fluid lines. We also think that is sure. There is even a dispute over whether handicraft is an industry. Some people think that handicraft is not an industry; it is just a skill or play skill.

Handicraft industry has a long history and played an extremely important role in the development of human history. Compared with mechanical industry, manual industry is much less efficient, but manual products contain more human elements and labor condensation, and more human wisdom and ability. Handicraft industry needed the commitment of workers. Products were usually fashioned by the employee. Every working procedure was the same subject of labor, and manufacturing can directly reflect people's own ability and more elegant appearance, and not through the mediation of the machine. The more you need someone to do it and do it directly, the more power and spirit you have. The handicraft products condense more human labor, more attention, more wisdom, and even more emotion and love. The craftsmen's job concentrated on handicraft, which was the basis and source of modern industry. Craftsmen concentrated on work and products were often single-minded, but not like machines, to spread out that human feelings among the same products were almost countless, each of these products could share the human nature and emotional input, were very few.

Comprehensive the historical development and realistic demand, we can use four words to define and explain the craftsman's spirit, and also establish it's analysis framework from four dimensions. Four concepts are the refinement, better, pursuit, and improvement. These words and concepts can make the research from multiple dimensions craftsmen education, cultivate and develop process possible. Firstly, the refinement describes the spirit development in a relatively static state, the stage is characterized by concentration, refers to consistently focus on an industry, product, technology, process, or in the development and improvement, represents the spirit of practical ethics. Secondly, the better is more and more in meaning, but it describes the craftsman's spirit in a dynamic process of development. The development of quantitative change and its phase is characterized by the inheritance, refers to the patient perseverance to long-term accumulation in certain areas. The inheritance way of dynamic will continue, skills and quality reflects the historical responsibility and stick to the quality. Thirdly, the pursuit describes that the craftsman's spirit is the continuation in the development and power source, the stage is characterized by the innovation, is the pursuit of the development of qualitative change, also refers to the artisans in the long-term process of accumulation and inheritance of the persistent pursuit and promotion of industry, product, process, quality, etc, the qualitative leap, and the cultivation of innovation ability and skill levels rising, represents the craftsman spiritual and creative aspect. Lastly, the improvement describes a craftsman spiritual goals and mission, and its phase is characterized by the excellence, can refer to the craftsmen through long-term unremitting to individuals and groups, accumulation, inheritance and innovation and gift industry, product, process or enterprise with great spiritual wealth, quality and reputation value, especially the sublimation of his craft, the quality and status in society, and represents the ideal pursuit of spirit. The craftsman's spirit can be consist of four aspects by the concentration, inheritance, innovation and outstanding. The analysis framework and educational dimensions also can be set from the angles of the art state, spirit, community, social contribution, and so on. The multiple dimensions of investigation clearly define the cultivation and transfer procedures, and training in the education laws of the craftsman's spirit.

\section{CULTIVATION PATHS OF CRAFTSMAN'S SPIRIT}

The cultivation of craftsman's spirit requires a good social education environment. This special spirit education has a style of spiral rising. All universities and colleges, especially vocational education as a starting point in knowledge acquisition and skill cultivation of artisans should strive to improve workplace education institutions by educating social responsibility and design process of education. The spirit should be to develop the education in the process of target attribute mapping to the practice of talent training of education, from the inheritance of knowledge and skill, shaping of the spirit of quality, the accumulation of social capital to the social responsibility of setting up, full range for craftsmen and master skills to construct good education environment.

\section{A. Takig the Cultivation of Craftsman's Spirit of as the Educational Spirit and Action Guideline}

As a guidance of the educational practice, educational idea, and development goals, educational spirit should project actively to the educational dimensions of craftsman's spirit; give the concentration, inheritance, innovation, and 
excellence to education action in the direction of character and behavior. The spiral properties of craftsman's spirit should be internalized in the thought, externalized in the action, and start from the concept and the guiding ideology in each link of the process and level of education not only with the skills masters to refinement and inheritance, but also with the innovation and excellence in the field of industry. The latter two, innovation and excellence, makes skills masters stand out from the crowd become leaders of the industry and society. In view of the present social cognition, for artisans in the spirit of innovation and excellence, two education dimensions should be given more attention, and in the education practice as the object of education into the endogenous innovation and development and the pursuit of excellence quality. This is the needs of the reform educational spirit, is also the demand of social development. Therefore, to the cultivation of craftsman's spirit, education in terms of knowledge, skills and attitudes in addition to be focused and heritage aspects of the practice need each other more than ever to explore how to give education object to innovation driving, the ability development, and the pursuit excellence, this is the new normal education and society under the inevitable requirement of the coordinated development of spiral type.

\section{B. Education System Realized the Interactive Development with the Talent Growth Laws and Social Needs}

On the one hand, the essential attribute of craftsman's spirit in the educational dimensions is based on the growth rules of talents and the requirement analysis of development in the economic and social. High-skill personnel will generate the need for higher-level education experience in their career and individual growth as the ascension of skill level, the sublimation of spirit quality, the accumulation of social capital, and the expansion of social contribution. On the other hand, the interaction between education and society has strengthened the contingency attribute of education. There is a system interaction between education and economic industry, the relationship between the two social subsystem by target, adaptation, integration and maintain four interact, so as to realize its own survival, maintain and evolve ${ }^{[8]}$.

\section{Education Process Realized the Integration with Internalization of Knowledge and Skills, Spirit and Quality, Social Capital and Social Responsibility to the Educational Object}

From the perspective of the vocational and technical education, education is a process of dynamic forming by knowledge, skills, and attitudes on the education object. It has the necessary time span and periodic. In the educational dimensions of craftsman's spirit, internalization of each dimension in education objects is the specific requirements in the process of education. Implement the integration and internalization should pay attention to cultivate their interest in industry and focus on quality in order to realize the students' coordinated development in vocational knowledge and skill level, to provide social opportunities for students, to achieve their own industry value, and to endow them with the internal motivation to the pursuit of excellence. Therefore, in the process of engineering education, we should optimize the combination and dynamic planning of education elements, education means and education contents, and change the current mismatch between education process and occupational factors. This combination will enable the education object and planning to leave the education place can be naturally when started his career in the application of knowledge, in the tradition of skills, with the help of social relations, and under the inner drive of social responsibility, through the career of production and work practice, focus on the production practice of expertise, professional knowledge, skills, and transmission of social relations, and carry out production, management and social innovation, realize the value of spirit of excellence.

\section{Education Elements Coupled with the Dimension of Talent Growth}

Education sites, education participants and education contents constitute the main elements of education practice. In the process of talent cultivation, these elements should be placed in the basic link of social production practice and coupled with the various dimensions of talent growth, so as to realize all-link collaborative education.

To the education sites, education has been extended from physical locations such as traditional classrooms, LABS and training centers to virtual world and Internet. On the other hand, we should attach great importance the cultural soft power construction to the spirit education, insist on paying equal attention to skill teaching and humanistic quality cultivation, and change the current education investment and cultural soft power to construct the hardware mismatch condition.

To the education participants, they are divided into teachers and students, and both of them should establish a benign interaction in education activities. In the spiral upward process of craftsmanship formation, teachers also are the carriers of knowledge and skill, and are key nodes that students enter the social networks from the industry edge in the craftsman social community. This requires teachers to have a industry background and industry link, to possess the process of analyze education, to promote students' learning and practice, to lead the students to enter industry practice, and to guide the students' creative ability and quality.

To the education content based on vocational education, the three elements of professional analysis, which are knowledge, skills, and attitudes, should be embedded into the various education modules, and be optimized to improve the education process. 


\section{REFERENCES}

[1] K. Q. Li, The Government Work Report-2016. Beijing: People's Publishing House, 2016. (In Chinese)

[2] K. Q. Li, The Government Work Report. Beijing-2017: People's Publishing House, 2017. (In Chinese)

[3] G. F. Yan and L. Zhang, "The educational dimensions and cultivation approached of craftsman's spirit," Journal of Higher Education Management, vol. 11, No. 6, pp. 67-73, November 2017. (In Chinese)

[4] D. Xue, "Study of Chinese craftsmanship", Vocational and Technical Education, vol. 36, No. 25, pp. 8-12, September, 2016. (In China)
[5] Y. L. Han and C. Q. Ma, "Cultivation of craftsmanship of applicationoriented talents", Journal of Hubei University of Education, Vol. 31, No. 6, June, 2016. (In Chinese)

[6] J. J. Liu, "Craftsman spirit and its contemporary value", Studies in Ideologocal Education, Sum. 267, No. 10, October, 2016. (In Chinese)

[7] Q. Z. Xiao and Y. C. Liu, "Craftsman spirit and its contemporary value", Studies in Ideologocal Education, Vol. 28, No. 6, June, 2016. (In Chinese)

[8] L. Zhang and G. F. Yan, "Research on the collaborative development path of vocational education and intelligent manufactur", Chniese Vocational and Technical Education, Vol. 24, No. 3, January, 2017. (In Chinese) 